\title{
Study of Latent Tuberculosis among Type 1 Diabetic Children in Zagazig University Pediatric Hospital
}

Saad Ahmed Mansour ${ }^{1}$, Ehab Abd Elhamid Abd Elsalam',

Rehab Ahmed Rabie ${ }^{2}$, Naglaa Fathy Abd Elrazik Ibrahim*1

Departments of ${ }^{1}$ Pediatrics and ${ }^{2}$ Medical Microbiology and Immunology,

Faculty of Medicine, Zagazig University, Egypt.

*Corresponding Author: Naglaa Fathy Abd Elrazik Ibrahim, Mobile: (+20)01066610307,

Email: doc.naglaafathy33@gmail.com

\section{ABSTRACT}

Background: In certain places, tuberculosis (TB) and diabetes mellitus (DM) are strongly linked as frequent comorbidities and might be termed epidemics combined. Objective: The present work aimed to detect relationship between type 1 DM (T1DM) and latent TB. Patients and Methods: This comparative cross-sectional study was conducted over the period from October 2019 to October 2020. It included 81 cases had type 1 DM and 81 healthy children as control group. This study was conducted at Zagazig University Pediatric Hospital. All patients were subjected to the following: Full history taking, full general examination, and investigation (Tuberculin test and chest $\mathrm{X}$ ray). Results: In the current study, $42 \%$ were male and (58\%) were female. In the present work, there was no statistically significant difference between cases group and controls group regarding anthropometric measurements. This study showed that, the percentage of positive tuberculin test was higher among cases group than controls group $(32.1 \%, 7.4 \%)$ $\mathrm{p}$ value $<0.001$. OR estimate for DM on risk of TB was 5.9 (95\% CI 2.27 to 15.33). Conclusion: There was no statistically significant difference between diabetic group and control group regarding sex, age, weight, and height. There was no statistically significant difference between diabetic and control group regarding contact with patient with TB and passive smoking. The percentage of positive tuberculin test was higher among diabetic group than control group. Keywords: Diabetes mellitus, Tuberculosis, Type 1 Diabetic Children.

\section{INTRODUCTION}

In certain places, tuberculosis (TB) and diabetes mellitus (DM) are strongly linked as frequent comorbidities and might be termed epidemics combined. When compared to nondiabetic individuals, diabetes doubles the chance of developing active tuberculosis after infection. DM can make TB therapy more difficult and/or hasten the progression of the illness ${ }^{(\mathbf{1})}$.

The pathophysiological basis for this association is thought to be mediated through alterations in the immune response against Mycobacterium tuberculosis ${ }^{(2)}$. This occurs through affection of both innate and adaptive immunity ${ }^{(3)}$. Affection of innate immunity occurs through accumulation of the advanced end-products of glycation that impair functions of phagocytes ${ }^{(4,5)}$. Regarding adaptive immunity, higher levels of interleukin 2 and T-cell helper 1 (interferon $\gamma$ ) and T-cell helper 17 cytokines and a lower frequency of natural T-regulatory cells $\left(\mathrm{CD} 4{ }^{+}, \mathrm{CD} 25^{+}\right.$, and $\left.\mathrm{CD} 127^{-}\right)$ are found in diabetic patients and increase the likelihood for TB coexistence ${ }^{(6)}$.

Because of the significant link between diabetes and tuberculosis, bidirectional screening is required to detect newly diagnosed diabetes in patients with active $\mathrm{TB}$ or latent $\mathrm{TB}$ infection in individuals with $\mathrm{DM}{ }^{(7)}$. Indeed, in areas with a high prevalence of diabetes, the risk of developing tuberculosis due to the illness outweighs that of the human immunodeficiency virus (8). The WHO recorded 1000000 cases of tuberculosis in the Middle East (880 000-1 200 000) ${ }^{\text {(9). In }}$ comparison, the International Diabetes Foundation claimed 35 million diabetes people in this region ${ }^{(\mathbf{1 0})}$. In Egypt, the prevalence of tuberculosis ranged from 14 to 44 cases per 100,000 , whereas diabetes incidence was $16.8 \%$. The proportion of DM in TB patients ranged from $16.4 \%$ to $29.3 \%$. ${ }^{(11,12)}$.

In spite of the fact that there are numerous techniques for screening latent pulmonary tuberculosis, there is no consensus on the standard screening test. For a long time, tuberculin skin test (TST) alone was used as a screening technique ${ }^{(1)}$.

The present work aimed to detect relationship between type $1 \mathrm{DM}$ and latent TB.

\section{PATIENTS AND METHODS}

This comparative cross sectional study was conducted over the period from October 2019 to October 2020. It included 81 cases who had type 1 DM and 81 healthy children as control group. This study was conducted at Zagazig University Pediatric Hospital.

\section{Ethical approval:}

This study was ethically approved from Institutional Reviewer Board (IRB) in Faculty of Medicine, Zagazig University Hospital and parental or caregivers' written consent from every case that participates in this research was taken. This work has been carried out in accordance with The Code of Ethics of the World Medical Association (Declaration of Helsinki) for studies involving humans.

Sample size: Two sided significance level 95(1-alpha) power (1-beta) \% chance 80 of detecting ratio of sample 
size, unexposed/exposed 1. Percent of unexposed with outcome $12 \%$ percent of exposed with outcome $30 \%$ odds ratio 3.1

- Risk / Prevalence ratio 2.5.

- Risk / Prevalence difference 18.

- Sample size of diabetic children 81 .

- Sample size of healthy children 81 .

- Total sample size 162.

Inclusion criteria: All children in this study aged from 1 to 18 years old.

Exclusion criteria: If diagnosed with type 1 diabetes for < 1 year, non-type 1 diabetes, no informed consent obtained, participation in another study at the time of recruitment, congenital or acquired immune deficiency disease, and steroids intake in the last 4 weeks.

All patients were subjected to the following: Full history taking, full general examination, and investigation.

Tuberculin test:

TB screening was done for both groups using TST. TST was administered by injecting $0.1 \mathrm{ml}$ of two tuberculin units of purified protein derivative (RT 23; Statens Serum Institute, Copenhagen, Denmark) into the volar surface of the forearm (intradermal) with a disposable syringe and a $27 \mathrm{G}$ needle. The maximal transverse size of induration, not the erythema, was read (in millimeters) $48-72 \mathrm{~h}$ later with a ball-point pen and a ruler ${ }^{(\mathbf{1 3})}$.

We used TST more than $10 \mathrm{~mm}$ as the cut-offvalue to determine TST positivity regardless of Bacillus Calmette-Guérin vaccination status ${ }^{(\mathbf{1 4})}$.

This procedure was carried out by a well-trained laboratory technician using the Mantoux technique. It was done to all cases, and it was repeated after 2 weeks in children who had negative test in $1^{\text {st }}$ time.

Chest x-ray: It was done for all cases.

\section{Statistical Analysis}

The collected data were tabulated and analyzed using SPSS version 24 software (Spss Inc, Chicago, ILL Company). Categorical data were presented as number and percentages. Chi square test $\left(\mathrm{X}^{2}\right)$ was used to analyze categorical variables. Quantitative data were expressed as mean \pm standard deviation, and range. Student " $t$ " test was used to analyze normally distributed variables among 2 independent groups. The accepted level of significance in this work was stated at 0.05 .

\section{RESULTS}

There was no statistically significant difference between cases group and controls group regarding sex and age (Table 1).

Table (1): Comparison between cases group and controls group regarding age and sex

\begin{tabular}{|c|c|c|c|c|c|c|c|}
\hline & & & $\begin{array}{c}\text { Cases } \\
\text { Group } \\
(\text { No.=81) }\end{array}$ & $\begin{array}{c}\text { Controls } \\
\text { group } \\
\text { (No.=81) }\end{array}$ & P. value & OR & $\begin{array}{c}95 \% \\
\text { Confidence } \\
\text { Interval }\end{array}$ \\
\hline \multirow{2}{*}{$\begin{array}{l}\text { Age } \\
\text { (years) }\end{array}$} & \multirow{2}{*}{\multicolumn{2}{|c|}{$\begin{array}{c}\text { Range } \\
\text { Mean } \pm \text { SDs }\end{array}$}} & $1.5-17$ & $1.5-17$ & \multirow{2}{*}{0.09} & & \\
\hline & & & $10.90 \pm 4.47$ & $9.90 \pm 4.20$ & & & \\
\hline \multirow{4}{*}{ Sex } & Tomolo & No. & 47 & 38 & \multirow{4}{*}{0.157} & \multirow{4}{*}{0.6} & \multirow{4}{*}{$0.34-1.19$} \\
\hline & F Cmate & $\%$ & $58.0 \%$ & $46.9 \%$ & & & \\
\hline & \multirow{2}{*}{ Male } & No. & 34 & 43 & & & \\
\hline & & $\%$ & $42.0 \%$ & $53.1 \%$ & & & \\
\hline
\end{tabular}

There was no statistically significant difference between cases group and controls group regarding weight and height (Table 2).

Table (2): Comparison between cases group and controls group regarding anthropometric measurements

\begin{tabular}{|c|c|c|c|c|c|c|}
\hline & & $\begin{array}{c}\text { Cases } \\
\text { Group } \\
(\mathbf{N o . = 8 1 )}\end{array}$ & $\begin{array}{c}\text { Controls } \\
\text { group } \\
(\mathbf{N o . = 8 1 )}\end{array}$ & $\begin{array}{c}\text { P. } \\
\text { value }\end{array}$ & OR & $\begin{array}{c}95 \% \\
\text { Confidence } \\
\text { Interval }\end{array}$ \\
\hline Weight (kg) & Mean \pm SDs & $40.05 \pm 14.74$ & $37.41 \pm 15.49$ & 0.268 & & \\
\hline \multirow{3}{*}{$\begin{array}{l}\text { Weight Z } \\
\text { Score }\end{array}$} & <-2 (Underweight) & $1(1.2 \%)$ & $2(2.5 \%)$ & \multirow{3}{*}{0.815} & \multirow{3}{*}{0.6} & \multirow{3}{*}{$\begin{array}{c}(0.038- \\
10.48) \\
(0.078- \\
4.34)\end{array}$} \\
\hline & $-2-2$ (Normal) & $49(60.5 \%)$ & $50(61.7 \%)$ & & & \\
\hline & $\begin{array}{c}>2 \text { (Overweight } \\
\text { and obese) }\end{array}$ & $31(38.3 \%)$ & $29(35.8 \%)$ & & & \\
\hline \multirow{2}{*}{ Height $(\mathrm{cm})$} & Range & $85-172$ & $90-167$ & \multirow{2}{*}{0.131} & & \\
\hline & Mean \pm SDs & $144.79 \pm 21.27$ & $139.67 \pm 21.72$ & & & \\
\hline \multirow{3}{*}{$\begin{array}{l}\text { Height Z } \\
\text { Score }\end{array}$} & $<-2$ (short stature) & $5(6.2 \%)$ & $7(8.6 \%)$ & \multirow{3}{*}{0.766} & \multirow{3}{*}{0.01} & \multirow{3}{*}{$\begin{array}{c}(0.001- \\
0.13)\end{array}$} \\
\hline & $-2-2($ Normal $)$ & $75(92.6 \%)$ & $74(91.4 \%)$ & & & \\
\hline & $>2$ (tall stature) & $1(1.2 \%)$ & $0(0.0 \%)$ & & & \\
\hline
\end{tabular}

There was no statistically significant difference between cases group and controls group regarding contact with patient with tuberculosis and passive smoking (Table 3). 
Table (3): Comparison between cases group and controls group regarding history of contact with patient with tuberculosis and history of passive smoking

\begin{tabular}{|c|c|c|c|c|c|c|c|}
\hline & & & $\begin{array}{c}\text { Cases } \\
\text { Group } \\
(\text { No.=81) }\end{array}$ & $\begin{array}{l}\text { Controls } \\
\text { group } \\
\text { (No.=81) }\end{array}$ & P. value & OR & $\begin{array}{c}95 \% \\
\text { Confidence } \\
\text { Interval }\end{array}$ \\
\hline \multirow{4}{*}{$\begin{array}{l}\text { Contact with } \\
\text { patient with } \\
\text { tuberculosis }\end{array}$} & \multirow{2}{*}{ No } & No. & 79 & 79 & \multirow{4}{*}{1.000} & \multirow{4}{*}{1} & \multirow{4}{*}{$0.137-7.27$} \\
\hline & & $\%$ & $97.5 \%$ & $97.5 \%$ & & & \\
\hline & \multirow{2}{*}{ Yes } & No. & 2 & 2 & & & \\
\hline & & $\%$ & $2.5 \%$ & $2.5 \%$ & & & \\
\hline \multirow{4}{*}{ Passive smoking } & \multirow{2}{*}{ No } & No. & 59 & 53 & \multirow{4}{*}{0.307} & \multirow{4}{*}{0.7} & \multirow{4}{*}{$0.36-1.38$} \\
\hline & & $\%$ & $72.8 \%$ & $65.4 \%$ & & & \\
\hline & \multirow{2}{*}{ Yes } & No. & 22 & 28 & & & \\
\hline & & $\%$ & $27.2 \%$ & $34.6 \%$ & & & \\
\hline
\end{tabular}

The mean of pulse, RR, temperature, age of onset of diabetes, which ranged between 0.5 and 15 , and the mean of duration of DM, which ranged between 1 and 11, are shown in table 4.

Table (4): Clinical manifestation, age of onset of diabetes and duration of DM among cases group

\begin{tabular}{||l|c|}
\hline & Mean \pm SD \\
\hline Pulse & $77.35 \pm 1.68$ \\
\hline Respiratory rate (RR) & $21.88 \pm 1.88$ \\
\hline Temperature & $37.00 \pm 0.234$ \\
\hline Age of onset of diabetes (years) & $7.64 \pm 4.39$ \\
\hline Duration of DM (years) & $3.31 \pm 3.02$ \\
\hline
\end{tabular}

The percentage of positive tuberculin test was higher among cases group than controls group (Table 5).

Table (5): Comparison between cases group and controls group regarding Tuberculin test.

\begin{tabular}{|c|c|c|c|c|c|c|c|}
\hline & & & $\begin{array}{c}\text { Cases } \\
\text { group } \\
(\text { No. }=81)\end{array}$ & $\begin{array}{c}\text { Controls } \\
\text { group } \\
\text { (No.=81) }\end{array}$ & P. value & OR & $\begin{array}{c}95 \% \\
\text { Confidence } \\
\text { Interval }\end{array}$ \\
\hline \multirow{4}{*}{$\begin{array}{l}\text { Tuberculin } \\
\text { test }\end{array}$} & \multirow{2}{*}{ Negative } & No. & 55 & 75 & \multirow{4}{*}{$<0.001$} & \multirow{4}{*}{5.9} & \multirow{4}{*}{$2.27-15.33$} \\
\hline & & $\%$ & $67.9 \%$ & $92.6 \%$ & & & \\
\hline & \multirow{2}{*}{ Positive } & No. & 26 & 6 & & & \\
\hline & & $\%$ & $32.1 \%$ & $7.4 \%$ & & & \\
\hline
\end{tabular}

There was no statistically significant difference between positive and negative tuberculin test regarding age, duration of DM and sex. There was statistically significant increase in HBA1C among positive than negative tuberculin test (Table 6).

Table (6): Comparison between positive and negative tuberculin test regarding (Age, Duration of DM, HBA1C and sex)

\begin{tabular}{|c|c|c|c|c|}
\hline & & $\begin{array}{c}\text { Positive tuberculin } \\
\text { test (No.=26) }\end{array}$ & $\begin{array}{c}\text { Negative tuberculin } \\
\text { test }(\text { No. }=55)\end{array}$ & P. value \\
\hline Age & Mean \pm SD & $9.52 \pm 5.40$ & $11.56 \pm 3.84$ & 0.054 \\
\hline Duration of DM & Mean \pm SD & $2.77 \pm 2.27$ & $3.56 \pm 3.31$ & 0.272 \\
\hline HBA1C & Mean \pm SD & $7.88 \pm 0.65$ & $7.42 \pm 0.52$ & $<0.001$ \\
\hline \multirow{2}{*}{ Sex } & Female & $12(46.2 \%)$ & $35(63.6 \%)$ & \multirow{2}{*}{0.137} \\
\hline & Male & $14(53.8 \%)$ & $20(36.4 \%)$ & \\
\hline
\end{tabular}




\section{DISCUSSION}

In the current study, $42 \%$ were male and $(58 \%)$ were female. Our results appear to be in line with literature data where female predominance was significant among Libyan (15). Our results are in harmony with Dabelea et $\boldsymbol{a l} .{ }^{(16)}$ who suggested a female predominance. Only a slight and not significant higher incidence of T1DM in Sudanese females ${ }^{(\mathbf{1 7})}$ and Kuwaiti males ${ }^{(\mathbf{1 8})}$ was reported, while no gender difference was observed among Tunisians ${ }^{(19)}$. In the study of Stipancic et al. ${ }^{(20)}$, there was no difference in the incidence between the sexes. The results of other studies are not uniform. Some studies have also shown no difference in incidence between the sexes ${ }^{(21)}$.

However, others have found the incidence to be greater in boys ${ }^{(22)}$, or in girls ${ }^{(23)}$. Hassan et al. ${ }^{(24)}$ aimed to study the prevalence of diabetes mellitus (DM) among school-age children in Menoufia governorate. In all, 8000 school-age children from rural and urban areas in Menoufia governorate aged between 6 and 15 years between September 2015 and September 2016 had been subjected to filling a written questionnaire based on criteria of WHO (2010) for diagnosis of DM, and detection of glucose in urine (Glucotest), as well as estimation of random blood glucose for children with positive glucotest. They found 30 were newly diagnosed diabetics (20 (66.6\%) cases were male and $10(33.3 \%)$ were female. This denotes the dominance of male sex with respect to this prevalence.

In the present work, there was no statistically significant difference between cases group and controls group regarding anthropometric measurements. This finding was comparable with that of Hassan et al. ${ }^{(24)}$ who found that there was no statistically significant difference between T1DM group and controls group regarding anthropometric measurements. Though there have been numerous reports on diabetic children's development issues, just a few research have focused on ultimate height ${ }^{(25)}$. It's still unclear if these characteristics are impacted just by the length of diabetes and the tightness of metabolic management, or by other factors as well ${ }^{(26)}$. Several papers have documented retarded growth and delayed puberty with T1DM even in reasonably controlled patients ${ }^{(27)}$, whereas many other studies found no effect of diabetes on growth ${ }^{(28)}$. Actually, in many reports, diabetic children were found to be taller at the onset of the disease compared with nondiabetic children and attained a final height greater than the predicted genetic target height ${ }^{(29)}$.

This study showed that the percentage of positive tuberculin test was higher among cases group than controls group $(32.1 \%, 7.4 \%)$. OR estimate for DM on risk of TB was 5.9 (95\% CI 2.27 to 15.33).
This is in agreement with a recent systematic review that concluded the pooled OR estimate for DM on risk of latent tuberculosis infection (LTBI) was 1.18 (95\% CI 1.06 to 1.30$)^{(30)}$. In similarity to our finding Martinez et al. ${ }^{(31)}$ showed that DM was associated with LTBI with OR 1.5 (95\% CI 1.0 to 2.2). In agreement also Leegaard et al. ${ }^{(32)}$, who found DM increased the risk of active TB disease with ORs ranging from 1.3 to 2.6 .

Our results are in harmony with Bakr et al. ${ }^{(1)}$ who conducted a cross-sectional study to assess the prevalence and pattern of latent pulmonary $\mathrm{TB}$ in diabetic children. A cross-sectional study was carried out in a Tertiary Care Hospital, Mansoura, Egypt, during the period from January to December, 2016. Their study enrolled all diabetic children with the inclusion criteria who were available during the study period and attending the endocrinology outpatient clinics or admitted in the inpatient ward. A total of 70 diabetic patients completed tuberculin skin test (TST) reading, and their results were compared with those of 70 healthy controls. They found that, TST was positive in $30 \%$ of the screened diabetic patients. Test positivity was significantly higher among diabetic group when compared with control group.

A recent meta-analysis study involving 13 observational studies reported latent TB prevalence of $22.8 \%{ }^{(30)}$. Jeon and Murray ${ }^{(33)}$ performed a metaanalysis of 13 observational studies and reported that diabetes mellitus was associated with an increased risk of TB with relative risk of 3.11 (95\% CI 2.27-4.26). In study done in Singapore, the prevalence of latent TB among diabetic patients was 28.2, 38.9, and $28.5 \%$, respectively ${ }^{(34)}$.

\section{CONCLUSION}

There was no statistically significant difference between diabetic group and control group regarding sex, age, weight and height. There was no statistically significant difference between diabetic and control group regarding contact with patient with $\mathrm{TB}$ and passive smoking. The percentage of positive tuberculin test was higher among diabetic group than control group.

\section{REFERENCES}

1. Bakr M, Elsharkawy A, Wahba Y et al. (2017): Prevalence of latent pulmonary tuberculosis in children with diabetes mellitus attending a Tertiary Care Hospital in Mansoura: a cross-sectional study. Alex J Pediatr., 30:94-

2. Niazi A, Kalra S (2012): Diabetes and tuberculosis: a review of the role of optimal glycemic control. J Diabetes Metab Disord., 11:28.

3. Restrepo B, Schlesinger L (2013): Host-pathogen interactions in tuberculosis patients with type 2 diabetes mellitus. Tuberculosis, 93:10-14. 
4. Nandy D, Janardhanan R, Mukhopadhyay D et al. (2011): Effect of hyperglycemia on human monocyte activation. J Investig Med., 59:661-667.

5. Hair P, Echague $C$, Rohn $R$ et al. (2012): Hyperglycemic conditions inhibit C3-mediated immunologic control of Staphylococcus aureus. J Transl Med., 10:35.

6. Kumar N, Sridhar R, Banurekha V et al. (2013): Expansion of pathogen-specific T-helper 1 and T-helper 17 cells in pulmonary tuberculosis with coincident type 2 diabetes mellitus. J Infect Dis., 208:739-748.

7. Jeon C, Harries A, Baker $M$ et al. (2010): Bidirectional screening for tuberculosis and diabetes: a systematic review. Trop Med Int Heal., 15:1300-1314.

8. Ruslami R, Aarnoutse R, Alisjahbana B et al. (2010): Implications of the global increase of diabetes for tuberculosis control and patient care. Trop Med Int Heal., 15:1289-1299.

9. World Health Organization (2014): Guidance for national tuberculosis programmes on the management of tuberculosis in children. 2nd ed. Geneva, Switzerland: WHO.

https://www.ncbi.nlm.nih.gov/books/NBK214448/

10.Atlas, IDF Diabetes (2017): Brussels, Belgium: International Diabetes Federation. In Sixth edition. URL: https://www. idf. org/component/attachments/attachments.html(2017).

11.Akl M, Mahalli A (2012): Drug resistant tuberculosis: risk factors and resources-utilization at a chest disease clinic, Alexandria, Egypt J Am Sci., 8:107-112

12. Alkabab Y, Al-Abdely H, Heysell S (2015): Diabetesrelated tuberculosis in the Middle East: an urgent need for regional research. Int J Infect Dis., 40:64-70.

13. Song $\mathrm{S}$, Yang J, Lee K et al. (2014): Comparison of the tuberculin skin test and interferon gamma release assay for the screening of tuberculosis in adolescents in close contact with tuberculosis TB patients. PLoS One, 9:100267.

14. Nayak S, Acharjya B (2012): Mantoux test and its interpretation. Indian Dermatol Online J., 3:2-6.

15. Kadiki O, Roaeid $R$ (2002): Incidence of type 1 diabetes in children (0-14 years) in Benghazi Libya (1991-2000) Diabetes Metab., 28:463-467.

16. Dabelea D, Bell R, D'Agostino R et al. (2007): Writing Group for the SEARCH for Diabetes in Youth Study Group. Incidence of diabetes in youth in the United States. JAMA., 297:2716-2724.

17.Elamin A, Omer $M$, Zein $K$ et al. (1992): Epidemiology of childhood type I diabetes in Sudan, 1987-1990. Diabetes Care, 15:1556-1559.

18. Shaltout A, Moussa M, Qabazard M et al. (2002): Kuwait Diabetes Study Group. Further evidence for the rising incidence of childhood Type 1 diabetes in Kuwait. Diabet Med., 19:522-525.

19. Ben Khalifa F, Mekaouar A, Taktak S et al. (1997): A five-year study of the incidence of insulin-dependent diabetes mellitus in young Tunisians (preliminary results) Diabetes Metab., 23:395-401.

20.Stipancic G, Sabolic L, Malenica M et al. (2008): Incidence and trends of childhood type 1 diabetes in Croatia from 1995 to 2003. Diabetes Res Clin Pract., 80:122-127.

21. Haynes A, Bower C, Bulsara $M$ et al. (2004): Continued increase in the incidence of childhood type 1 diabetes in a population-based Australian sample (19852002). Diabetologia, 47:866-870.

22. Casu A, Pascutto C, Bernardinelli L et al. (2004): Type 1 diabetes among Sardinian children is increasing: the Sardinian diabetes register for children aged 0-14 years (1989-1999). Diabetes Care, 27:1623-1629.

23. Ionescu-Tîrgovişte C, Guja C, Călin A et al. (2004): An increasing trend in the incidence of type 1 diabetes mellitus in children aged 0-14 years in Romania - ten years (1988-1997) EURODIAB study experience. J Pediatr Endocrinol Metab., 17:983-991.

24. Hassan F, Khatab A, Abo El-Fotoh W et al. (2019): Prevalence of diabetes mellitus among school-age children. Menoufia Med J., 32:305-10.

25.Penfold J, Chase H, Marshall G et al. (1999): Final adult height and its relationship to blood glucose control and microvascular complications in IDDM. Diabet Med., 12:129-133.

26. Herber S, Dunsmor I (1998): Does control affect growth in diabetes mellitus? Acta Paediatr Scand., 77:303-305.

27.Lebl J, Schober E, Zidek T et al. (2003): Growth data in large series of 587 children and adolescents with type 1 diabetes mellitus. Endocr Regul., 37:153-161.

28. Jos J, Meteyer I, Farkas D et al. (1996): Growth of children with insulin-dependent diabetes. Study of 104 cases. Arch Pediatr., 3:218-228.

29. Songer T, LaPorte R, Tajima $\mathbf{N}$ et al. (1996): Height at diagnosis of insulin-dependent diabetes in patients and their non-diabetic family members. $\mathrm{Br}$ Med J., 292:1419-1422.

30.Lee M, Huang Y, Kuo Y et al. (2017): Diabetes mellitus and latent tuberculosis infection: a systematic review and Metaanalysis. Clin Infect Dis., 64:719-27.

31. Martinez L, Zhu L, Castellanos M et al. (2017): Glycemic control and the prevalence of tuberculosis infection: a population-based observational study. Clin Infect Dis., 65:2060-8.

32. Leegaard A, Riis A, Kornum J et al. (2011): Diabetes, glycemic control, and risk of tuberculosis. A populationbased case-control study. Diabetes Care, 34:2530-5.

33.Jeon C, Murray M (2008): Diabetes mellitus increases the risk of active tuberculosis: a systematic review of 13 observational studies. PLoS Med., 5:152-156.

34. Leow M, Dalan R, Chee $C$ et al. (2014): Latent tuberculosis in patients with diabetes mellitus: prevalence, progression and public health implications. Exp Clin Endocrinol Diabetes, 122:528-532. 